\title{
How Best to Prevent Future Persons From Suffering: A Reply to Benatar ${ }^{1}$
}

\author{
Brooke Alan Trisel \\ P.O. Box 876 \\ Hilliard, Ohio \\ USA, 43026 \\ triselba@cs.com
}

\begin{abstract}
David Benatar claims that everyone was seriously harmed by coming into existence. To spare future persons from this suffering, we should cease having children, Benatar argues, with the result that humanity would gradually go extinct. Benatar's claim of universal serious harm is baseless. Each year, an estimated $94 \%$ of children born throughout the world do not have a serious birth defect. Furthermore, studies show that most people do not experience chronic pain. Although nearly everyone experiences acute pain and discomforts, such as thirst, these experiences have instrumental value. For example, when a person picks up a hot object, in response to the pain, the person releases the object, thereby preventing serious harm. The standard that Benatar uses to evaluate the quality of our lives is arbitrary, as I will demonstrate. His proposal that we phase humanity out of existence by ceasing to have children is misguided and an overreaction to the problem of human suffering. The 'threshold conception of harm', which is a targeted approach for preventing future persons from suffering, is a more sensible approach.
\end{abstract}

\section{Introduction}

There are billions of potential people we could bring into existence. How many additional people should we create? 'Zero' is the response given by David Benatar. In his provocative book, Benatar (2006) claims that everyone was seriously harmed by coming into existence. To spare future persons from this suffering, he argues that it would be best if we ceased having children, with the result that humanity would gradually go extinct.

Because the quality of our lives is very bad, Benatar claims, he argues that it is generally, all things considered, morally wrong to procreate. I will dispute both of these claims. I will argue that the quality of our lives, on average, is good according to an objective list account of well-being. This paper will contribute to the literature on this

1 Thanks to Thaddeus Metz for helpful comments. Also, thanks to David Benatar and to the other participants at the November 2011 workshop on anti-natalism at the University of Johannesburg for their comments. 
topic by demonstrating that pain and discomforts have instrumental value and that we are better off having the capacity to feel pain than we would be without this capacity.

Also, I will point out similarities between Benatar's envisioned ideal world and the idea of heaven, and will demonstrate that such a standard for judging the quality of our lives is arbitrary. Benatar's universal anti-natalism can be thought of as a proposed solution to the problem of human suffering, but this solution is an overreaction to the problem. To prevent future persons from suffering, some philosophers have argued that prospective parents should refrain from bringing a new person into existence unless the life of that new person would be worth living or above some other specified level of well-being - the so-called 'threshold conception of harm'. This view can be thought of as an alternative approach for preventing future persons from suffering. I will argue that this approach makes more sense than universal anti-natalism.

\section{The 'Procreational Russian Roulette'}

Before discussing Benatar's arguments, it is important to provide context for understanding the arguments. Benatar writes: 'procreation is usually the consequence of sex rather than the result of a decision to bring people into existence' (2006: 2). Benatar's claim is substantiated by studies. For example, it is estimated that $49 \%$ of all births in the United States (U.S.) in 2001 were unintended (Finer \& Henshaw 2006: 90).

Thus, in almost half of these births, new people were brought into existence and no consideration was given to the quality of their lives. Nonetheless, after they entered the world, many of these individuals were embraced, loved, and taken well care of by their parents. In contrast, some new people were born into extreme poverty. Others entered the world infected with HIV or addicted to cocaine. Benatar refers to people's procreational habits as a 'procreational Russian roulette'. The loaded gun is aimed, not at their own heads, 'but at those of their future offspring' (2006: 92).

Although an estimated $51 \%$ of the births in the U.S. were intended, this does not necessarily mean that the parents gave any consideration to the quality of life that would be experienced by the future persons. When deciding whether to have a child, sometimes the prospective parents do consider that the future person may be born with a serious congenital disorder, such as Down syndrome. However, when they consider this risk, I suspect that many of them are thinking of how the birth of the child with the disorder would affect the quality of their own lives, as opposed to how it would affect the quality of life of the new person.

Over the last forty years, there has been extensive debate regarding whether non-existent future persons have rights and what, if any, obligations we have to future persons. Some philosophers have argued that prospective parents have an obligation to refrain from bringing a child into existence unless the quality of that child's life would be above a certain threshold. ${ }^{2}$ For example, Jeff McMahan contends that parents should refrain from bringing a child into existence unless the life of that child would be 'objectively worth living' (1998: 226-228). More recently, Eduardo Rivera-López has proposed a higher threshold by arguing that it is prima facie wrong for prospective parents to bring a child into existence if that child "will suffer a non-trivial disability or disadvantage, even if we also know that her life will be worth living' (2009: 352).

To spare future persons from suffering, Benatar argues that it would be best not to bring any additional human beings into existence. Those philosophers who support the threshold conception of harm are also seeking a way to prevent future persons from

2 For more background on the threshold conception of harm, see Meyer 2010. 
suffering. With this targeted approach, prospective parents would refrain from bringing into existence a select group of future persons - those whose lives would not be worth living or who would fall below some other threshold of well-being. This approach is a form of selective anti-natalism, which contrasts with Benatar's universal anti-natalism.

Some future persons do experience serious harm by coming into existence and so it is understandable why the threshold conception of harm would be proposed as an approach to prevent suffering. In contrast, Benatar goes well beyond this by arguing that we should voluntarily phase humanity out of existence. As discussed next, Benatar believes that everyone was seriously harmed by coming into existence, not just those who are born with a serious congenital disorder or those who are born into severe poverty.

\section{Introducing Benatar's Two Arguments}

Benatar makes two independent arguments for his conclusion that it is generally, all things considered, morally wrong to procreate. His first argument, in rough form, is that we seriously harm potential persons by bringing them into existence, but that we do not benefit them in any way. This 'asymmetry argument' will not be discussed here. $^{3}$

Benatar makes a second argument - the one that I will dispute - for his conclusion that we are wrong to procreate and that it would be better if we had never been born. Taking into account the good and bad features of our lives, as well as other factors such as the order of the good and bad in our lives, he claims that everyone was seriously harmed by coming into existence. Because all of our lives are very bad, it is generally wrong, he argues, to bring additional human beings into existence. Benatar paints a gloomy picture of human life. He points out that there are wars, natural disasters, and incidences of murder and starvation throughout the world. He also argues that everyone experiences 'negative mental states daily or more often. These include hunger, thirst, bowel and bladder distention (as these organs become filled), tiredness, stress, thermal discomfort (that is, feeling either too hot or too cold), and itch' (2006: 71).

Despite the pain and discomfort that we experience, most people do not think that their lives are bad, as Benatar acknowledges. On the contrary, they think that their lives 'go quite well' (2006: 64). If our lives are bad, as Benatar contends, then why do most people think that their lives are good? How do we explain this glaring discrepancy? Has one person, namely Benatar, misjudged that all of our lives are bad, as I will argue, or have vast numbers of people from different cultures throughout the world all misjudged that their lives are good, as Benatar argues?

Benatar claims that there are three psychological phenomena that explain these favorable assessments of our lives. He argues that the most influential of these phenomena is a tendency towards optimism - what psychologists refer to as the Pollyanna ${ }^{4}$ Principle, unrealistic optimism, or optimistic bias. Benatar points to studies suggesting that people have a tendency to remember positive rather than negative experiences. People ignore or downplay the bad in their lives, Benatar argues.

3 Earlier commentators on this argument include Belshaw 2007, Smilansky 2008, Harman 2009, DeGrazia 2010, Spurrett 2011, and Metz 2011.

4 Pollyanna is a child from fictional literature who looked on the bright side of everything, including every misfortune. 
Benatar discusses two other psychological phenomena (2006: 67-68), but indicates that they may lead one to overstate or understate the quality of one's life. Thus, Benatar concludes that 'it is only Pollyannaism that inclines people unequivocally towards more positive assessments of how well their life is going' (2006: 68).

Earlier commentators have not challenged Benatar's claim that people have a tendency towards optimism. To convince us that our positive assessments of our lives are inaccurate because of optimistic bias, Benatar relies heavily on psychological studies. It is important that we take a closer look at these studies to see whether the study populations were representative of 'people' in general. Reginald Smart (1966) points out that most psychological studies used college undergraduates as the study population. He also points out that the college population differs considerably from the adult non-college population in many characteristics such as age, social class, and learning ability. In a systematic review of psychological studies that Benatar points to as evidence that 'people' have an optimistic bias, Shelley Taylor and Jonathon Brown do indicate that many studies did find that 'most people' have an optimistic bias. However, they also indicate that 'much of the evidence' for optimistic bias comes from research with college students (1988: 194). Benatar also refers to the book The Pollyanna Principle by Margaret Matlin and David Stang. In a study of Pollyannaism by Matlin and Valerie Gawron, they indicate that their study population consisted of 'young, white, middle-class students from Upstate New York and Long Island' (1979b: 412). ${ }^{5}$

Despite earlier warnings from Smart and others about sample selection bias in psychological studies, the problem has persisted. ${ }^{6}$ The psychologist Jeffrey Arnett analyzed studies published from 2003 through 2007 in six premier journals of the American Psychological Association. Although the U.S. accounts for less than 5\% of the world's population, the study populations were predominantly American, according to Arnett. As part of his analysis, Arnett analyzed the study populations from studies published in the Journal of Personality and Social Psychology. He found that $67 \%$ of the samples from the American studies, and $80 \%$ of the samples from the studies performed in other countries, consisted solely of undergraduate psychology students (2008: 604).

In pointing to research findings discussed by Ronald Inglehart (1990: 243), Benatar notes that self-assessments of happiness vary between countries, but that 'everywhere there is a tendency towards optimism'. (2006: 66). Later research has raised doubt about the universality of optimistic bias. ${ }^{7}$ For example, regarding their findings in a cross-cultural study of Canadian and Japanese psychology students, Steven Heine and Darrin Lehman conclude: "This cultural difference suggests that the "normality" of self-enhancing biases might be specific to Western cultures' (1995: 605).

As demonstrated, because of sample selection bias, the findings from the studies on optimistic bias cannot be generalized to 'people' in general. Furthermore, studies have found that many Japanese students have a pessimistic bias, which is the tendency to expect that negative events are more likely to occur to oneself than to others. ${ }^{8}$ For these reasons, the most that can be concluded from the studies of optimistic bias is that many undergraduate psychology students in Western countries have such a bias.

5 For additional examples of studies on Pollyannaism by Matlin where undergraduate students were the study population, see Matlin and Stang 1975 and Matlin et al. 1979a.

See Peterson 2001, Arnett 2008, and Henrich et al. 2010.

See Markus and Kitayama 1991.

See, for example, Chang and Asakawa 2003. 


\section{Why We Are Better Off Having the Capacity to Experience Pain}

Benatar purportedly considers the good and bad in our lives in his evaluation of the quality of our lives. However, in his book, there is little discussion of love, family, friendship, aesthetic enrichment, accomplishment, and autonomy - some of the positive features of life that make life worth living. ${ }^{9}$ One approach to responding to Benatar's argument would be to provide a more balanced picture by pointing out all of the objective goods in life. Another approach would be to argue, as Elizabeth Harman does, that 'some features of a life are very valuable, and can easily outweigh many mundane discomforts' (2009: 783). Instead of pursuing these approaches, I will dispute Benatar's claim regarding the amount of bad in our lives and will do so for the following reason. Most people already recognize the positive features in life. However, very few people realize that many of the experiences that Benatar counts as 'bad', such as acute pain and thirst, are beneficial, as I will demonstrate.

Benatar believes that pain is intrinsically bad, meaning that pain is bad 'in itself' ${ }^{10}$ Many people share this view. Are pain and discomforts something that we would be better off without, as most people assume, or do pain and discomforts have an important instrumental value, meaning that they have value as a means for realizing certain desirable ends?

To help determine whether we would be better off without pain, we can look at a summation of clinical case studies of individuals who experience no pain - those born with the rare condition of 'congenital insensitivity to pain'. ${ }^{11}$ It might be thought that these individuals are fortunate to live their lives without pain, but this is far from the truth. Ronald Melzack and Patrick Wall describe the lives of individuals who are born without the ability to feel pain: 'Many of these people sustain extensive burns, bruises and lacerations during childhood, frequently bite deep into the tongue while chewing food, and learn only with difficulty to avoid inflicting severe wounds on themselves' (1996: 3-4).

Elna Nagasako has indicated that 'the observation that these people often die in childhood because they fail to notice injuries and illnesses has been viewed as compelling evidence that the ability to perceive pain has great survival value' (2003: 213). Pain serves three valuable purposes (Melzack and Wall 1996: 3). First, pain alerts a person to the threat of harm. Upon feeling pain, one immediately reacts by avoiding the source of the pain, which prevents serious injury. For example, when one picks up a hot object and feels pain, one reacts by immediately releasing the object, which prevents the object from burning the skin and underlying tissue. When we experience certain types of pain, such as the pain that occurs from touching a hot object, we learn to avoid such experiences in the future, which is a second valuable purpose served by pain. When a person sustains a serious injury, such as a leg fracture, the pain limits the person's activity and promotes a period of rest, which is important for the body's natural repair system to work effectively. This is a third valuable purpose served by pain.

A distinction should be made between acute pain and chronic pain. Acute pain, such as that which occurs by spraining an ankle, has a brief duration. In contrast, chronic pain has a duration of many months and, in some cases, can last for years. Acute pain

9 Benatar does include some discussion about meaning in life (2006: 83).

10 A distinction is typically made between the following four types of value: final value, instrumental value, intrinsic value, and extrinsic value. For further discussion, see Korsgaard 1983.

11 This condition has in the past been referred to by various other names such as 'congenital analgesia'. See Nagasako 2003. 
has value from a biological perspective whereas chronic pain no longer serves a biologically useful purpose. A person who has an arm or leg amputated may continue to experience severe 'phantom' limb pain for years. However, as Melzack and Wall write, they gain 'nothing from the pain. Pain such as this now becomes a problem in its own right' (12). The late philosopher Nikola Grahek (2007), and the renowned physician Paul Brand (1997), had argued that our capacity to feel pain is a gift. However, they were also well aware that pain is a gift that nobody wants. At this point, one might agree that acute pain is valuable for warning us of threats, but think that it would be better if these threat warnings were experienced, not as pain, but as pleasure or some other pain-free sensation. Suppose that the threat warnings were felt, not as pain, but as a mild squeezing sensation. What would occur in this scenario? Many people would ignore the mild squeezing sensations and would be badly injured as a result. ${ }^{12}$ Even when the threat warnings are felt as pain, some people ignore them. For example, some athletes who have sustained an injury, and are eager to return to their sport, will play despite the pain, which often delays healing.

If threat warnings were experienced as pleasure, we would not ignore them, but what would happen under this scenario? With our current physiology, when one picks up a hot object, the pain deters one from holding on to the object, which prevents serious harm. If the threat warnings were experienced as pleasure, when one picks up a hot object, the pleasure would provide an incentive to hold on to the hot object as long as possible, with the result that serious harm would occur. As the object burned through more and more tissue, the pleasure would intensify.

One might respond that we, as rational beings, would begin to recognize that pleasure precedes harm and so, to avoid being harmed, we would try to resist the temptation of pleasure. When we feel pain, we immediately react, without thinking about it, by withdrawing from the source of the pain. If we experienced the threat warnings in the form of pleasure instead of pain, we would not react as quickly. The pain-free warning systems that were examined above would not be nearly as effective in protecting us from harm as the warning system that we have.

As noted earlier, Benatar argues that discomforts such as thirst, feeling too hot or too cold, and the feeling of bladder distention contribute to making our lives bad. Regarding these discomforts, Harman writes: 'I think these experiences are often neutral or even good' (2009: 782). Harman does not expand on this thought. There is, however, strong scientific support for the belief that these discomforts have instrumental value. These discomforts alert a person to a threat to his or her body. For example, if one did not feel bladder fullness, the bladder would continue to fill with urine and eventually rupture, with the result that urine - a waste product - would leak into areas of the body where it can cause serious harm. ${ }^{13}$ Of all the discomforts that we experience, we should perhaps be the most grateful for the feeling of thirst. Michael McKinley and Alan Johnson write: 'Thirst is a subjective perception that provides the urge for human and animals to drink fluids. It is a component of the regulatory mechanisms that maintain body fluid homeostasis and ultimately is essential for survival' (2004: 1).

Homeostasis refers to the ability of the human body to maintain a relatively constant internal environment - which is needed for cells to function properly - despite poten-

12 Brand (1997: 191-197), who treated patients who lacked the ability to feel pain, attempted to devise 'a practical substitute for pain' that would alert his patients to threats. This warning system consisted of artificial sensors that would trigger a piercing sound or blinking lights. Brand indicates that the patients simply ignored or manually interrupted this warning system.

13 See Parker et al. 2009. 
tially large fluctuations in the external environment. Benatar argues that feeling too hold or too cold contribute to the bad in our lives. One way that the body maintains homeostasis is by providing us with feedback. When one feels too hot or too cold, one adjusts to this feedback by, for example, sitting in the shade when it is hot or putting on a coat when it is cold. Thus, the feedback, in the form of thermal discomfort, is of critical importance for helping to protect us from serious harm. ${ }^{14}$

After reading Better Never to Have Been, one might assume that the quality of our lives would be much better if we were unable to experience pain or discomforts. However, this is a false assumption, as demonstrated above. Because acute pain and discomforts are essential for protecting us from serious harm, the quality of our lives, on the whole, could not be much better than what it is today. In the next section, I will argue that the quality of our lives is high enough such that it will often be morally permissible for prospective parents to bring a new person into existence.

\section{Do the Benefits to Parents Outweigh the Potential Harm to Future Persons?}

Despite his anti-natalism, Benatar acknowledges that having children can yield benefits to the parents of the new person and to other people. He notes that parents find fulfillment in raising children, that children are an insurance policy for old age, and that children provide parents with quasi-immortality (1997: 351; 2006: 88, 98). ${ }^{15}$ Because he understands the benefits to parents and others from procreating, he also recognizes that his proposal for a phased extinction would be detrimental to some existent people. For example, in discussing the question of how quickly extinction should occur, he writes: 'in some situations failing to bring people into existence can make the lives of existent people a lot worse than they would otherwise have been' (2006: 184). Benatar has indicated that: 'One way, then, to defend the having of children, even if one accepts my view that existence is a harm, is to deny that that harm is great. One could then argue that the harm is outweighed by the benefits to the parents' (1997: 351).

It is undeniable that serious congenital anomalies are harmful to persons coming into existence. However, in assessing how much harm is experienced by new persons, we must ask ourselves the following question. What percentage of new persons have a serious congenital anomaly? The geneticist Arnold Christianson et al. estimate that, each year, $6 \%$ of children born throughout the world have a serious birth defect (2006: 2). Regarding Benatar's claim that everyone is seriously harmed by coming into existence, if the $6 \%$ figure is correct, then this indicates that $94 \%$ of new people do not have a serious birth defect. Furthermore, many children throughout the world are born into good conditions, are well cared for by their parents, and never experience serious harm in their lives.

In contrast to acute pain, chronic or persistent pain has no instrumental value. A World Health Organization study found that $22 \%$ of primary care patients experienced persistent pain in the prior year. ${ }^{16}$ In other words, $78 \%$ of the primary care patients in the study did not experience persistent pain in the prior year.

14 For a discussion of thermoregulation, see Blatteis 1998.

15 For discussion of whether there is a duty to procreate and how having children can enrich our lives, see Smilansky 1995 and Spurrett 2011.

16 Gureje et al. 1998. Persistent pain was defined as pain that was present most of the time for six months or more during the prior year. The study was conducted at 15 centers throughout the world. Other studies may report lower or higher percentages of people who experience chronic pain. There are often in- 
Serious birth defects and chronic pain are bad, but most people do not experience these problems. Furthermore, as demonstrated earlier, we are better off having the capacity to experience acute pain and discomforts than we would be without this capacity. As mentioned, individuals who are born without the capacity to feel pain often die during childhood. Benatar asserts that everyone was seriously harmed by coming into existence, but an examination of this claim has revealed that it is baseless. For Benatar to conclude that everyone was seriously harmed, he must be conceiving of 'serious harm' in a very broad and unusual way. If a person who experiences nothing more than common pains and discomforts would file a 'wrongful life' lawsuit and claim that he had been seriously harmed by being brought into existence, the lawsuit would be dismissed for being unfounded and frivolous. The judge would rightly wonder 'Where is the alleged serious harm?'

If the quality of our lives is very bad, as Benatar claims, then it would be difficult to imagine that they could be worse. However, we can easily imagine that the quality of our lives could be much worse. We could live in caves and be without the modern conveniences that we take for granted, such as clean running water and electrically powered lights. We could spend all of our time hunting for food and not have time to pursue other interests. We could be without antibiotics and other medicines to fight disease. We could have an average life expectancy of 25 years and children could go without a decent education.

As suggested, the quality of our lives is much better than that of our distant ancestors. We are fortunate to be living at a time in human history where the quality of life is good for large numbers of people.

Because Benatar overstates how many people are harmed by coming into existence, the argument that the benefits to parents (and others) from having children outweigh the potential harm to new persons is much stronger than Benatar had assumed. In many instances, the benefits to prospective parents from having a child will outweigh the potential harm to the new person.

\section{The Desire for Heaven on Earth}

Pessimists and religious apologists often disagree about whether God exists. However, there is one thing that pessimists and some religious apologists have in common. They both use unreasonable (i.e., extreme and unfair) standards. Some religious apologists claim, for example, that life is meaningless or is not 'truly' meaningful unless God exists and there is everlasting bliss in heaven. ${ }^{17}$ There is a striking similarity between Benatar's envisioned ideal world, in which there are human beings but no suffering, and the idea of heaven, as I will show.

According to Colleen McDannell and Bernhard Lang (2001), there are two accounts of heaven, one that is anthropocentric and one that is theocentric. In the theocentric account, heaven is God-oriented and is the timeless experience of contemplating the greatness of God. In contrast, heaven, in the anthropocentric account, is people-oriented. Jerry Walls, a philosopher of religion, writes: 'There the emphasis is upon being reunited with family and friends. In its most fully developed version, heaven is essentially like this life, without, of course, the evil and suffering that mar our present

consistencies in how chronic pain is defined and measured, which may explain some of the variation in the findings across studies.

17 Metz (2009: 192) argues that the desire for perfection underlies the standards adopted by proponents of supernaturalism about life's meaning. 
happiness' (2002: 7). According to Revelation 21.4 of the Bible (NRSV), 'Death will be no more; mourning and crying and pain will be no more. . .'.

Thus, in the anthropocentric view of heaven, the idea that there will be human beings, but without suffering is a prominent feature. In the ideal world envisioned by Benatar, human beings are also without suffering. Another prominent feature of the idea of heaven is that one's existence in heaven is everlasting. Benatar argues that 'Coming into existence is bad in part because it invariably leads to the harm of ceasing to exist' (2006: 213). Thus, Benatar's standard for judging whether a life is worth starting seems to demand that life be everlasting. If it were not everlasting, then the harm of ceasing to exist would occur, which would mean that the person's life would not have been worth starting.

The idea of heaven has been fading. As McDannell and Lang explain: 'The modern heaven ... has become the minority perspective during the twentieth century. Rich and detailed accounts of the afterlife, accepted in the nineteenth century, are labelled as absurd, crude, materialistic, or sheer nonsense' (322). Walls attempts to resurrect the idea of heaven. He is concerned that because the universe may end billions of years from now that this somehow makes our lives pointless. He writes: 'If the universe will conclude in this fashion, everything can finally seem pointless' (175).$^{18}$

Benatar makes a useful distinction between whether a life is worth starting and whether a life is worth continuing (2000: 176; 2006: 22). He argues that a higher standard should be used to judge whether future lives are worth starting than should be used to judge whether our lives are worth continuing (2006: 213). Our lives are very bad, he argues, but they might not be so bad that we should seek to end our lives.

Benatar argues, in the context of the 'asymmetry' rationale, that even a small amount of bad would make a future person's life not worth starting (2006: 48). Thus, according to Benatar's standard, perfection, in the form of the complete absence of any amount of bad, is required for a life to be worth starting. Once started, for a person's life to be 'good', it would have to be better than the lives of nearly everyone in existence today. Benatar claims that high quality lives are 'exceedingly uncommon' (2006: 92).

There is nothing wrong with having a desire for a post-life heaven or a desire to live our current lives everlastingly and without any bad in them - a heaven on Earth. However, as I will argue in the following section, it is inappropriate to turn these desires into standards for judging whether life is meaningful (as Walls does) or whether future lives are worth starting (as Benatar does).

\section{Benatar's Arbitrary Standard}

Benatar argues that it is sometimes appropriate to appeal to a human perspective when making certain kinds of judgments, such as those related to distributive justice (2006: 86). However, he argues that it is more appropriate to assess the quality of our lives sub specie aeternitatis or from the point of view of the universe. ${ }^{19}$ This latter phrase, which originated with Henry Sidgwick, is a bit misleading because, if taken literally, it suggests that the universe has a perspective independent of sentient beings. Without sentient beings, the universe would not have a perspective. What Benatar means by 'perspective of the universe' is that we can view ourselves from a detached external

18 In Trisel (2002) and (2004), I respond to this argument.

19 In response, Metz (2011: 252-253) argues that the human perspective would be what is most likely to have enabled human beings to evolve and hence to have grounded value judgments. 
standpoint - one that encompasses times long before humanity existed and long after humanity will be extinct. From this objective view, our lives are meaningless, Benatar argues (2006: 83).

In trying to convince us that our lives are very bad, Benatar argues that human beings endure a period of frustration before fulfilling a desire. He writes: 'It is logically possible for desires to be fulfilled very soon after they arise, but given the way the world is, this does not usually happen' (2006: 74-75). Also, he indicates: 'From the human perspective, what we take to be worthwhile is very much determined by the limits of what we can expect. For instance, since none of us lives until age 240, people tend not to think that failing to reach that age makes one's life go less well' (2006: 82). Benatar indicates that 'Perhaps the good life is something that is impossible to attain. It certainly sounds as though a life that is devoid of any discomfort, pain, suffering, distress, stress, anxiety, frustration, and boredom, that lasts for much longer than ninety years . . . would be better than the sort of life the luckiest humans have' (2006: 82).

Standards must be context specific. Benatar considers and rejects this possible objection to his argument that we should judge the quality of our lives sub specie aeternitatis. He argues that 'we sometimes do and should judge the brightest people by supra-human standards' (2006: 86). However, he fails to provide any examples where this has occurred. Furthermore, even if this has occurred, it does not necessarily mean that it was appropriate.

\section{The Extreme Standard}

Benatar does not explicitly outline a standard for judging the quality of our lives, but based on his comments, his standard is as high as, if not higher than, the following Extreme (E) standard:

(E) A human's life is good only if: (1) there is no pain or negative mental states; (2) one's desires, as they arise, are fulfilled in 15 minutes or less; and (3) one will have a lifespan of at least 240 years. ${ }^{20}$

If one adopts such an extreme standard, then one will conclude that the quality of our lives is very bad. This raises the question of whether it is appropriate to adopt such a high standard. Should we should assess the quality of our lives based on what is logically possible, as Benatar does, or based on what is nomologically (i.e., physically) possible given the actual laws and limitations of the universe? An outcome might be logically possible, but physically impossible. For example, suppose a person has a desire to become a renowned novelist. To avoid any frustration in fulfilling this desire, she hopes to achieve the goal in five minutes. However, before doing so, she must think of an interesting story, write her novel, find a publisher, and then have it read by people - all in a matter of five minutes. This would be physically impossible. There are limits on how quickly a person can think and write.

Although we can imagine a world that is devoid of frustration, stress, pain, and discomforts, it would be inappropriate to judge the quality of our lives by that standard. Standards must be based on what is nomologically possible, not on logically possible, but nomologically impossible, conditions. When standards are based on logically pos-

20 I have not sought to include all of the values/disvalues that might be included in a standard. I selected three that were discussed by Benatar: absence of pain, desire fulfillment, and length of life. 
sible, but nomologically impossible, conditions, arbitrariness is the result, as I will demonstrate.

\section{The Super Extreme Standard}

In what follows, I will be comparing the Extreme standard to two other standards. Suppose that someone proposes the following Super Extreme (SE) standard:

(SE) A human's life is good only if: (1) there is no pain or negative mental states; (2) one's desires, as they arise, are fulfilled in a minute or less; and (3) one will have a lifespan of at least 50,000 years.

Of the Extreme and Super Extreme standards, which one is more appropriate to judge the quality of our lives? Both of the standards are logically possible, but nomologically impossible, given the known actual laws of the universe. Without being grounded in the context of what is nomologically possible, there is no way to determine which of these standards is more appropriate than the other, which is what I mean when I indicate that the standards become arbitrary. One might try to argue that the Extreme standard is more appropriate because it is not as far out of our reach as the Super Extreme standard, but this would be invoking the concept of nomological possibility.

Because the Extreme and Super Extreme standards disregard the actual laws of the universe, they end up being arbitrary and simply reflect the personal preferences of various individuals. Thus, the standards become arbitrary and relative.

\section{The Perfection Standard}

If the standard for assessing the quality of our lives is based on logically possible, but nomologically impossible, conditions, then whatever a person happens to desire, no matter how outlandish, could be proposed as a standard for judging the quality of our lives, as long as it was logically possible. For example, one might propose the following Perfection $(\mathrm{P})$ standard.

(P) A human's life is good only if: (1) there is no pain or negative mental states; (2) one's desires, as they arise, are fulfilled instantaneously; and (3) one will live forever.

As argued earlier, Benatar uses the Perfection standard to assess whether the lives of future persons are worth starting. If a person proposed that the Perfection standard should be used to judge the quality of our lives, Benatar would have no basis on which to argue that the Extreme or Super Extreme standards are more appropriate than the Perfection standard. As shown, standards which are logically possible, but nomologically impossible, become arbitrary and relative.

As argued, Benatar's standard for judging the quality of our lives is at least as high as the Extreme standard. His standard may be as high as the Perfection standard. If he uses the Perfection standard to judge the quality of our lives, then this would be inconsistent with maintaining that a higher standard should be used to judge whether life is worth starting than whether life is worth continuing.

It is logically possible for a species with advanced physical and intellectual capabilities to exist on another planet. Benatar would argue that we should compare the quality of our lives to their lives and that our lives, in comparison, are very bad. Benatar suggests that context matters for some judgments, but not for those related to quality 
of life (2006: 84-86). Context-free standards become arbitrary. Why compare our lives to the Advanced species? Rather, why not compare our lives to the lives of moles? Moles live underground in tunnels and in solitude. Compared to moles, human beings are extremely intelligent, live long lives, and have a very high quality of life. If context is irrelevant, as Benatar suggests, then judging the quality of human lives based on a comparison with moles would be appropriate.

Benatar might argue that it is more appropriate to compare our lives to the Advanced species than to moles, but on what basis? If he argued that our lives are more similar to the Advanced species than to moles, then he would be appealing to context, which would contradict his claim that context is irrelevant. Context is relevant, which explains why we must judge the quality of our lives using human standards.

Benatar judges the quality of our lives based on a combination of what is logically possible and from sub specie aeternitatis. Is it appropriate to include the totality of what is logically possible as part of sub specie aeternitatis? This is unclear. Suppose that we view ourselves from an external standpoint, as if we are looking down on Earth from the Hubble telescope. From this standpoint, our view reflects, not the totality of what was logically possible, but what actually unfolded according to the laws of the universe and what could unfold in the future according to those same laws.

Thomas Nagel's The View From Nowhere (1986) is the best known contemporary work regarding the external perspective. In that work, he discusses the capacity of an individual to transcend his or her own "particular point of view and to conceive of the world as a whole' (3). Thus, Nagel does not refer to all logically possible events or worlds, but to the world. Based on this and other comments, ${ }^{21}$ it does not appear that Nagel includes the totality of what is logically possible as part of the external perspective, which suggests that philosophers might be conceiving of sub specie aeternitatis in different ways. This topic merits further examination in the future.

\section{Concluding Remarks}

There is a lively debate among demographers regarding whether we are approaching a limit on life expectancy. ${ }^{22}$ If we are nearing a limit on life expectancy, then this raises the following question. Taking into account what is nomologically possible, how much better could the quality of our lives be than what they are today? We might find better treatments for some diseases. Also, through lifestyle changes, such as exercising more, we might be able to prevent some chronic diseases and some chronic pain. However, as living organisms, we will still be vulnerable to disease, injury, stress, and natural disasters. Furthermore, even if we could do so through genetic engineering, it would be unwise for us to eliminate our capacity to experience acute pain and discomforts.

Of course, one way to increase the average quality of life for people throughout the world would be to focus on improving the lives of people who have a below average quality of life. Improving the quality of their lives would be physically possible. But could the lives of people who have a high quality of life be much better than what they are today? Based on what is nomologically possible, there is not much room for improvement in the quality of their lives. Future persons could not have a much higher quality of life than a person of today who has a high quality life.

21 See also pp. 4-9, 210, 212, and 216.

22 See Olshansky et al. (2001 and 2005) and Oeppen and Vaupel (2002). 
Although I have been critical of Benatar's views, I respect his work. Benatar's book is important for challenging us to reflect more deeply about why we have children and for bringing attention to current procreational practices that sometimes harm new people. Regarding the question posed in this essay of what is the best approach for preventing future persons from suffering, Benatar would argue that, because the quality of our lives is very bad, the best approach is to not bring any more children into the world. However, as I have demonstrated, Benatar uses an arbitrary and, therefore, inappropriate standard to assess the quality of our lives. In taking into account what is nomologically possible, the quality of our lives, on average, is good from an objective list account of well-being. Universal anti-natalism is an overreaction to the problem of human suffering.

Benatar's recommendation that people stop having children will likely be ignored, as he predicted (2006: 225). Consequently, it is not a viable option for preventing future persons from suffering. Even if it were a viable option, it would not be the best option. The threshold conception of harm is a more sensible approach for preventing future persons from suffering.

\section{References}

Arnett, J. 2008. 'The Neglected 95\%: Why American Psychology Needs to Become Less American', American Psychologist 63(7), 602-614.

Belshaw, C. 2007. 'Better Never to Have Been: The Harm of Coming into Existence', Notre Dame Philosophical Reviews. http://ndpr.nd.edu/review.cfm?id=9983. Accessed May 6, 2011.

Benatar, D. 1997. 'Why It is Better Never to Come into Existence', American Philosophical Quarterly 34(3), 345-355.

Benatar, D. 2000. 'The Wrong of Wrongful Life', American Philosophical Quarterly $37(2), 175-183$.

Benatar, D. 2006. Better Never to Have Been: The Harm of Coming into Existence. Oxford: Clarendon Press.

Blatteis, C. (ed.) 1998. Physiology and Pathophysiology of Temperature Regulation. London: World Scientific Publishing Co.

Brand, P. \& Yancey, P. 1997. The Gift of Pain. Grand Rapids, MI.: Zondervan.

Chang, E. \& Asakawa, K. 2003. 'Cultural Variations on Optimistic and Pessimistic Bias for Self Versus a Sibling: Is There Evidence for Self-Enhancement in the West and for Self-Criticism in the East When the Referent Group is Specified?', Journal of Personality and Social Psychology 84(3) 569-581.

Christianson, A., Howson, C., \& Modell, B. 2006. March of Dimes Global Report on Birth Defects: The Hidden Toll of Dying and Disabled Children. White Plains, N.Y.: March of Dimes Birth Defects Foundation. http://marchofdimes.com/downloads/Birth_Defects_Report-PF.pdf. Accessed July 3, 2011.

DeGrazia, D. 2010. 'Is it Wrong to Impose the Harms of Human Life?: A Reply to Benatar', Theoretical Medicine and Bioethics 31, 317-331. 
Finer, L. \& Henshaw, S. 2006. 'Disparities in Rates of Unintended Pregnancy in the United States, 1994 and 2001', Perspectives on Sexual and Reproductive Health 38(2), 90-96.

Grahek, N. 2007. (2 $2^{\text {nd }}$ ed.) Feeling Pain and Being in Pain. Cambridge: MIT Press.

Gureje, O., Von Korff, M., Simon, G., \& Gater, R. 1998. 'Persistent Pain and Well-Being', JAMA 280(2), 147-151.

Harman, E. 2009. 'Critical Study. David Benatar. Better Never to Have Been: The Harm of Coming into Existence', Nous 43(4) 776-785.

Heine, S. \& Lehman, D. 1995. 'Cultural Variation in Unrealistic Optimism: Does the West Feel More Invulnerable Than the East?', Journal of Personality and Social Psychology 68(4), 595-607.

Henrich, J., Heine, S., \& Norenzayan, A. 2010. 'The Weirdest People in the World?', Behavioral and Brain Sciences 33(2/3), 1-75.

Inglehart, R. 1990. Culture Shift in Advanced Industrial Society. Princeton: Princeton University Press.

Korsgaard, C. 1983. 'Two Distinctions in Goodness', The Philosophical Review 92(2), 169-195.

Markus, H. \& Kitayama, S. 1991. 'Culture and the Self: Implications for Cognition, Emotion, and Motivation', Psychological Review 98(2), 224-253.

Matlin, M. \& Stang, D. 1975. 'Some Determinants of Word-Frequency Estimates', Perceptual and Motor Skills 40(3), 923-929.

Matlin, M. \& Stang, D. 1978. The Pollyanna Principle: Selectivity in Language, Memory and Thought. Cambridge MA: Schenkman Publishing.

Matlin, M., Stang, D., Gawron, V., Freedman, A., \& Derby, P. 1979a. 'Evaluative Meaning as a Determinant of Spew Position', The Journal of General Psychology $100,3-11$.

Matlin, M. \& Gawron, V. 1979b. 'Individual Differences in Pollyannaism', Journal of Personality Assessment 43(4), 411-412.

McDannell, C. \& Lang, B. 2001. ( $2^{\text {nd }}$ ed.) Heaven: A History. New Haven: Yale University Press.

McKinley, M. \& Johnson, A. 2004. 'The Physiological Regulation of Thirst and Fluid Intake', News in Physiological Sciences 19, 1-6.

McMahan, J. 1998. 'Wrongful Life: Paradoxes in the Morality of Causing People to Exist' in Rational Commitment and Social Justice: Essays for Gregory Kavka, ed. J. Coleman. Cambridge: Cambridge University Press, 208-247.

Melzack, R. \& Wall, P. 1996. ( $2^{\text {nd }}$ ed.) The Challenge of Pain. London: Penguin Books. Originally published 1982.

Metz, T. 2009. 'Imperfection as Sufficient for a Meaningful Life: How Much is Enough?' in New Waves in Philosophy of Religion, ed. Y. Nagasawa \& E. Wielenberg. New York: Palgrave Macmillan, 192-214.

Metz, T. 2011. 'Are Lives Worth Creating?', Philosophical Papers 40(2), 233-255. 
Meyer, L. 2010. 'Intergenerational Justice' in The Stanford Encyclopedia of Philosophy, ed. E. Zalta. http://plato.stanford.edu/archives/spr2010/entries/justice-intergenerational/.

Nagasako, E., Oaklander, A., \& Dworkin, R. 2003. 'Congenital Insensitivity to Pain: An Update', Pain 101(3), 213-219.

Nagel, T. 1986. The View From Nowhere. Oxford: Oxford University Press.

Oeppen, J., Vaupel, J. 2002. 'Broken Limits to Life Expectancy', Science 296(5570), 1029-1031.

Olshansky, S. J., Carnes, B., Désesquelles, A., 2001. 'Prospects for Human Longevity', Science 291(5508), 1491-1492.

Olshansky, S. J., Passaro, D., Hershow, R., Layden, J., Carnes, B., Brody, J., Hayflick, L., Butler, R., Allison, D., \& Ludwig, D., 2005. 'A Potential Decline in Life Expectancy in the United States in the $21^{\text {st }}$ Century', The New England Journal of Medicine 352(11), 1138-1145.

Parker, H., Hoonpongsimanont, W., Vaca, F., \& Lotfipour, S. 2009. 'Spontaneous Bladder Rupture in Association with Alcoholic Binge: A Case Report and Review of the Literature', The Journal of Emergency Medicine 37(4) 386-389.

Peterson, R. 2001. 'On the Use of College Students in Social Science Research: Insights from a Second-Order Meta-analysis', Journal of Consumer Research 28, 450-461.

Rivera-López, E. 2009. 'Individual Procreative Responsibility and the Non-Identity Problem', Pacific Philosophical Quarterly 90, 336-363.

Smart, R. 1966. 'Subject Selection Bias in Psychological Research', Canadian Psychology $7 \mathrm{a}(2), 115-121$.

Smilansky, S. 1995. 'Is There a Moral Obligation to Have Children?', Journal of Applied Philosophy 12(1), 41-53.

Smilansky, S. 2008. 'Better Never to Have Been: The Harm of Coming into Existence. By David Benatar', The Philosophical Quarterly 58(232), 569-571.

Spurrett, D. 2011. 'Hooray for Babies', South African Journal of Philosophy 30(2), 197-206.

Swenson, W. 1980. 'Sample Selection Bias in Clinical Research', Psychosomatics 21(4), 291-292.

Taylor, S. \& Brown, J. 1988. 'Illusion and Well-Being: A Social Psychological Perspective on Mental Health', Psychological Bulletin 103(2), 193-210.

Trisel, B.A., 2002. 'Futility and the Meaning of Life Debate', Sorites 14, 70-84.

Trisel, B.A., 2004. 'Human Extinction and the Value of Our Efforts', The Philosophical Forum 35(3), 371-391.

Walls, J. 2002. Heaven: The Logic of Eternal Joy. Oxford: Oxford University Press. 